\title{
ANÁLISE DA COBERTURA DO SOLO DA ÁREA DE ENTORNO DE TRÊS UNIDADES DE CONSERVAÇÃO LOCALIZADAS NO ESTADO DE SÃO PAULO ${ }^{1}$
}

\section{LAND COVER ANALYSIS OF SURROUNDING REGION FOR THREE STATE PARKS LOCATED IN SÃO PAULO STATE, BRAZIL ${ }^{1}$}

\author{
Silva, A.M. ${ }^{2}$ \\ ${ }^{1}$ Parte de um projeto financiado pela FAPESP. Processo 00/12939-0. \\ ${ }^{2}$ Laboratório de Ecologia Isotópica - CENA - USP, Piracicaba - SP. E- \\ mail: amsilva@cena.usp.br.
}

\section{RESUMO}

O objetivo deste trabalho foi levantar informações sobre a cobertura do solo numa faixa de entorno de 3000 metros para as Unidades de Conservação (UCs): Parques Estaduais Intervales, Morro do Diabo e Vassununga, localizadas no Estado de São Paulo. Com base em imagens de satélite a classificação das cenas foi realizada por interpretação visual. Utilizando-se o software Idrisi uma faixa tampão de 3.000 metros foi criada no entorno da área de cada UC. Este mapa foi sobreposto com o mapa de cobertura anteriormente criado, objetivando recortar e isolar a área a ser estudada. Os resultados indicam uma situação distinta de cobertura do solo entre as UCs. No entorno do P. E. Morro do Diabo a classe de cobertura do solo predominante foi a pastagem $(\approx 43 \%)$, para o P. E. Vassununga foi a cana-de-açúcar $(\approx 34 \%)$ e para o P. E. Intervales foi a vegetação natural remanescente $(\approx 96 \%)$. Estas informações indicam que os parques estaduais Vassununga e Morro do Diabo possuem um alto grau de isolamento e as informações complementares obtidas junto à bibliografia ratificam os riscos de impactos ambientais que são previstos devido à situação dos usos da terra do entorno destas UCs. Para o caso do P. E. Intervales a preocupação maior é com a exploração ilegal do palmito (Euterpe edulis) e com a possível instalação de empresas mineradoras na região, o que poderia comprometer a manutenção da integridade da UC e da qualidade de vida da população. 
Palavras-chave: uso / cobertura do solo, entorno de fragmentos florestais, efeito de borda, fragmentação florestal.

\section{ABSTRACT}

The goal of this study was to survey information about the land cover in a 3,000 meters buffer region for three state parks located in São Paulo State (Intervales, Morro do Diabo and Vassununga). The study was carried out using digital satellite images and a visual classification method was used in order to classify the scenes. Applying the Idrisi software, a 3,000 meters buffer region surrounding each park was created and overlayed with the land cover map previously mentioned in order to isolate the region of interest for this study. The results indicate a distinct land cover for the buffer regions. For the Morro do Diabo state park the predominant land cover class was the pasture $(\approx 43 \%)$, while for Vassununga state park was the sugar-cane $(\approx 34 \%)$ and for Intervales state park was the remaining natural vegetation $(\approx 96 \%)$. Such surveyed information show that the Vassununga and Morro do Diabo state parks have a high degree of isolation and the complementary information found on bibliography confirms the environmental risks that are expected due the situation of land use on the buffer region around the parks. For Intervales state park the major concern is with the illegal exploration of the species Euterpe edulis and the possible installation of mining enterprises that could hazard the integrity of the park and the quality life of the surrounding population.

Key-words: land use / land cover, forest patch surrounding, edge effect, forest fragmentation.

\section{INTRODUÇÃO}

O tipo de vizinhança constitui um dos principais fatores que afetam a conservação da biodiversidade em fragmentos ou glebas florestais, juntamente com o tamanho e a forma do fragmento, seu grau de isolamento e histórico de perturbações. Estes fatores apresentam relações com fenômenos biológicos e processos ecológicos que afetam a natalidade e a mortalidade de plantas como, por exemplo, o efeito de borda, a deriva genética e as interações entre plantas e animais (VIANNA E PINHEIRO, 1998). A permeabilidade da paisagem para a locomoção da fauna é uma característica da paisagem que também é afetada pelo tipo de vizinhança 
dos fragmentos. A análise desses fatores é fundamental para identificar estratégias conservacionistas e prioridades para pesquisa.

O levantamento da cobertura do solo constitui uma atividade fundamental para o planejamento regional, na medida em que os efeitos do uso desordenado do solo acarretam vários impactos no ambiente (KOFFLER, 1993). Esta atividade permite, por exemplo, identificar o tipo de vizinhança que ocorre nas adjacências de um fragmento florestal ou Unidade de Conservação, perfazendo uma informação crucial no diagnóstico detalhado do entorno local da Unidade de Conservação. Isto pode facilitar uma posterior aproximação entre o corpo gestor das UCs e as populações, proporcionando um envolvimento mais direto com a gestão da unidade (SÃO PAULO, 1998).

Neste contexto, imagens de satélites constituem excelentes recursos para tal finalidade, pois proporcionam uma visão integrada e ampla do alvo estudado. Por sua vez, o emprego de técnicas e recursos de geoprocessamento agiliza os trabalhos e ainda permite a investigação de situações hipotéticas (cenários de uso da terra futurísticos e/ou pretéritos, por exemplo) caso seja de interesse do usuário (CALIJURI, 1996).

O Estado de São Paulo - sendo a unidade federativa do Brasil que contém a maior população humana, alguns dos maiores índices de produção agrícola do país e também expressivos índices de crescimento urbano - possui, por um lado, uma ampla biodiversidade ainda pouco conhecida em seus pormenores (JORGE ET AL., 2001) e, por outro, uma avançada área já desmatada (VIANNA E PINHEIRO, 1998), restando poucos relictos de vegetação natural, alguns reconhecidos pelo poder público como Unidades de Conservação.

Como a cobertura do solo ao longo da área do Estado de São Paulo é geograficamente variável, é esperado que o uso da terra no entorno de UC's localizadas em diferentes regiões também o seja. Isto permite a investigação comparativa do uso da terra no entorno das UC's, bem como dos possíveis riscos e/ou impactos ambientais que este(s) uso(s) pode(m) estar causando, cujos exemplos são mencionados a seguir.

Vianna e Pinheiro (1998), estudando o efeito da vizinhança para um fragmento florestal em Arapotí, Estado do Paraná, verificaram que áreas do fragmento que faziam fronteira com pastagem estavam sujeitas a um efeito de borda mais intenso do que áreas adjacentes ocupadas por reflorestamento de Pinus sp., dado que a área basal média de indivíduos arbóreos localizados na borda do fragmento apresentou aumento significativo a partir da borda e a altura média e o número de espécies se mantiveram sempre inferior às áreas cuja vizinhança era o Pinus sp..

No caso da fauna, Jorge et al. (2001) compararam a abundância e riqueza de espécies de pequenos mamíferos (marsupiais e roedores) 
ocorrentes nas várias fitofisionomias existentes em dois ambientes: na gleba Pé-de-Gigante (remanescente de vegetação natural - Parque Estadual de Vassununga) e em eucaliptal (reflorestamento) adjacente à gleba.

Verificaram que, para os roedores, a maior riqueza e abundância foi na vegetação natural, mais especificamente na faixa de vegetação ripária, enquanto que no eucaliptal ocorreu apenas uma espécie de roedor e o número de indivíduos registrados foi o menor dentre as fitofisionomias. Os marsupiais também mostraram clara preferência de habitat, sendo que no eucaliptal ocorreu apenas uma única espécie e a maior parte das espécies ocorreram de forma mais expressiva também na vegetação natural (também mais especificamente nas matas ciliares).

Pires et al. (2002) investigaram os movimentos de mamíferos de pequeno porte entre fragmentos de Floresta Atlântica e circunvizinhados por uma matriz de pasto, localizados na Reserva Biológica "Poço das Antas" (RJ), buscando compreender os processos sobre o grau de isolamento da fauna nestes fragmentos. Os fragmentos eram em número de oito e suas áreas variaram de 1,3 a 15,0 hectares e suas distâncias de 60 a 1.300 metros. Os autores observaram o movimento de sete espécies de marsupiais e cinco espécies de roedores. Destas espécies, sete delas foram consideradas "móveis", ou seja, os indivíduos se locomoviam entre os fragmentos. Foi notado, principalmente para os marsupiais, que alguns indivíduos praticamente adotaram alguns fragmentos como sua residência fixa e permanência constante, enquanto outros permaneciam num único fragmento e ocasionalmente trafegavam entre outros. Já outros indivíduos realmente nunca saíam de um determinado fragmento, constituindo populações isoladas. Duas espécies de marsupiais habitavam todos os fragmentos com certo grau de locomoção, sendo consideradas espécies generalistas em termos de habitat, uma vez que suportavam atravessar a "barreira" interfragmento que era formada pela matriz de pasto. Algumas espécies de roedores foram comuns na matriz de vegetação aberta, enquanto os marsupiais foram caracterizados como moradores de áreas de florestas. Um fato importante observado foi que nos fragmentos estudados, o efeito de borda afetou mais fortemente a dinâmica da fauna do que a área do fragmento propriamente dito e todas as espécies que persistiram foram hábeis a usar as bordas dos fragmentos, pois estas espécies parecem ser subgrupos de um grupo maior existente antes do processo de fragmentação.

Estabeleceu-se como objetivo do presente estudo realizar uma análise da cobertura do solo numa faixa de entorno de 3000 metros em três Unidades de Conservação (UC) localizadas no Estado de São Paulo: Parque Estadual Morro do Diabo, Parque Estadual de Vassununga e Parque Estadual Intervales. 
Frisa-se aqui que as cartas de cobertura do solo, das quais foram extraídas as informações aqui apresentadas na forma tabular, não foram aqui apresentadas por constituírem um material que, ao mesmo tempo, torna oneroso o trabalho de editoração e também limita muito a visualização clara do material por parte do leitor, quer seja no formato impresso ou em arquivo do tipo "Portable Document File (pdf)". Sendo assim, caso haja o interesse por parte do leitor em adquirir os mapas digitais para serem consultados e/ou trabalhados em software de geoprocessamento (Idrisi), basta entrar em contato com o autor solicitando cópias digitais.

\section{Localização e caracterização ambiental das áreas de estudo}

As três áreas de estudo: Parque Estadual Morro do Diabo (P.E.M.D.), Parque Estadual de Vassununga (P.E.V.) e Parque Estadual Intervales (P.E.I.), localizam-se no Estado de São Paulo (Figura 1).

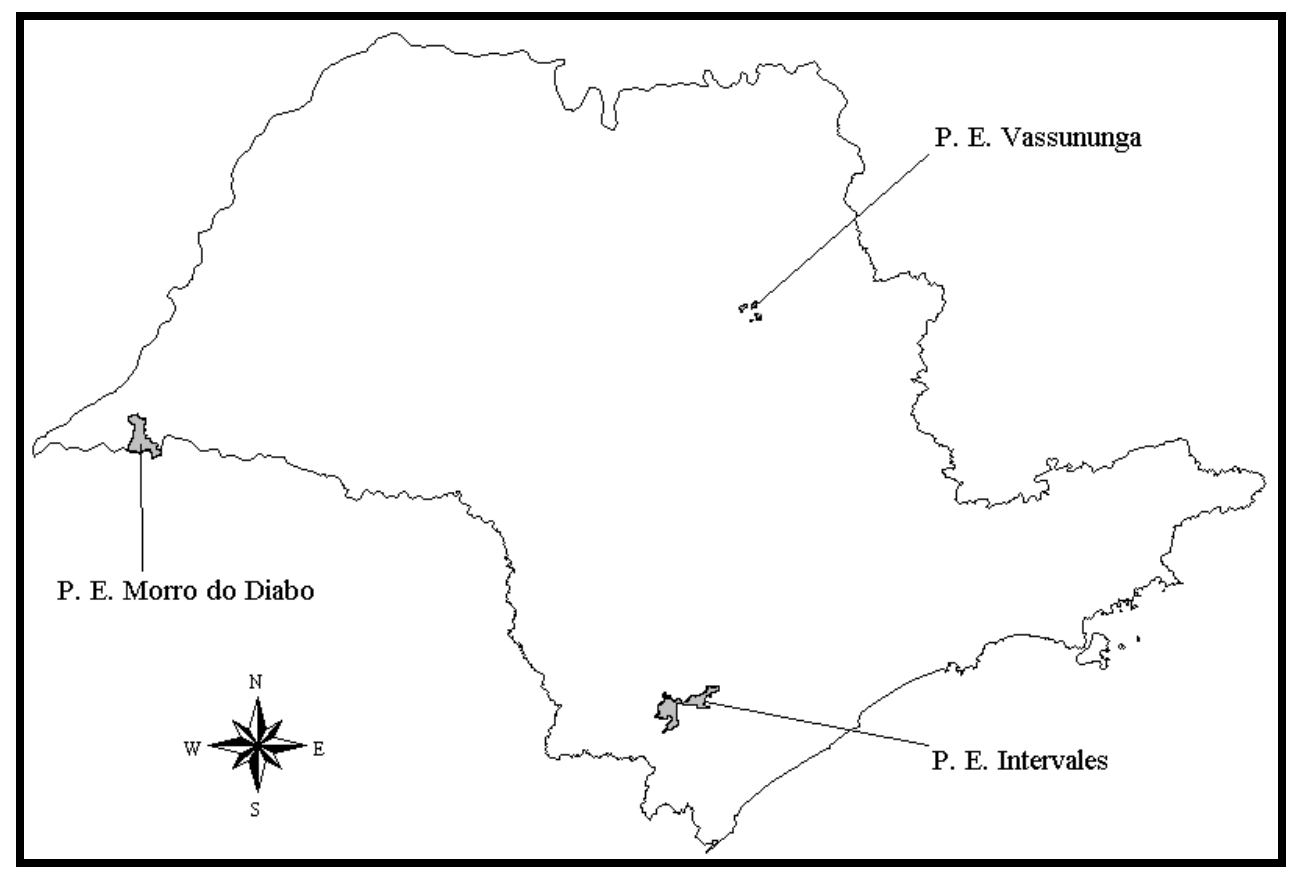

Figura 1 - Localização das UCs no estado de São Paulo.

Cada uma delas possui peculiaridades ambientais, conforme visto a seguir. Deve-se frisar que no atlas eletrônico do programa Biota da FAPESP (2003) há a possibilidade de averiguação detalhada da localização geográfica de cada uma das UCs aqui estudadas bem como a sobreposição 
com outro tipos de mapas, proporcionando uma complementação de informações num contexto de cartografia digital.

\section{Parque Estadual Morro do Diabo}

O P.E.M.D. é composto de uma única gleba cuja área é de 338,453 $\mathrm{km}^{2}$. Localiza-se no extremo oeste do Estado de São Paulo, na região denominada Pontal do Paranapanema. O clima predominante é do tipo Tropical de Altitude (ROSS, 2003). O embasamento geológico é formado pela bacia sedimentar do Paraná com litologias do grupo Bauru. O relevo predominante é suave-ondulado de colinas e morros com encostas suavizadas (ROSS, 2003), com predomínio de vegetação do tipo Floresta Estacional Semi-Decidual (SCHLITTLER, 1990). Os solos predominantes são do tipo Argissolos e Latossolos, com alguma ocorrência de Neossolos, todos altamente susceptíveis à erosão por serem predominantemente arenosos (OLIVEIRA et al., 1999).

\section{Parque Estadual de Vassununga}

Esta UC é formada por 6 glebas de dimensões distintas. A área total do parque soma $20,690 \mathrm{~km}^{2}$. A gleba denominada Pé-de-Gigante, a maior delas, possui $12,129 \mathrm{~km}^{2}$, as outras cinco glebas são: Capão da Várzea $\left(0,121 \mathrm{~km}^{2}\right)$, Capetinga Oeste $\left(3,278 \mathrm{~km}^{2}\right)$, Praxedes $\left(1,527 \mathrm{~km}^{2}\right)$, Maravilha $\left(1,270 \mathrm{~km}^{2}\right)$ e Capetinga Leste $\left(2,365 \mathrm{~km}^{2}\right)$. O parque localiza-se na região nordeste do Estado, no município de Santa Rita do Passa Quatro.

O clima é do tipo Tropical de Altitude. O relevo dominante na região é suavemente ondulado (ROSS, 2003) e os solos são predominantemente arenosos, prevalecendo o Latossolo Vermelho-Amarelo e a Areia Quartzosa (OLIVEIRA et al., 1999). A vegetação regional compreende as fisionomias normalmente encontradas no bioma Cerrado, ou seja, formas savânicas, Florestas Semi-Decíduas de Interflúvio, Florestas Ripárias e campos úmidos, normalmente ocorrendo um mosaico destas formações dentro da área das glebas, especialmente a Pé-de-Gigante (JORGE et. al., 2001).

\section{Parque Estadual Intervales}

O P.E.I. é formado por uma única gleba, a qual possui uma área de $498,88 \mathrm{~km}^{2}$. Situa-se na porção sul do Estado de São Paulo e o clima é do tipo Subtropical. A geologia regional é composta por três grandes conjuntos de unidades rochosas: 1) unidades relacionadas ao embasamento cristalino; 2) unidades de rochas metassedimentares e 3) os granitóides 
intrusivos. O parque estende-se predominantemente sobre a serra de Paranapiacaba, onde o relevo é fortemente dissecado (São Paulo, 1998). A vegetação é formada predominantemente por Floresta Ombrófila Densa, genericamente denominada Mata Atlântica. Há certa variação espacial da vegetação, determinada pela variação do embasamento geológico e características do relevo (SÃO PAULO, 1998). Ocorre uma predominância de solos do grupo Cambissolos, porém ocorrendo também Argissolos, Latossolos e Neossolos (OLIVEIRA et al., 1999).

\section{METODOLOGIA}

Para as três Unidades de Conservação foram utilizadas imagens do satélite Landsat 5. Para o P.E.V. utilizou-se a cena 220/75 de agosto de 1996, adquirida junto ao Instituto Nacional de Pesquisas Espaciais e por intermédio do Laboratório de Geoprocessamento do Instituto Florestal de São Paulo. Para o P.E.M.D., utilizou-se a cena 223/76 de março de 1987 e para o P.E.I. utilizou-se a cena $220 / 77$ de setembro de 1990 . Todas as cenas são multiespectrais (sensor TM - bandas 3, 4 e 5) e as duas últimas cenas mencionadas foram adquiridas gratuitamente junto ao sistema "Earth Science Data Interface (ESDI, 2004)", consultado em janeiro de 2004 (http://glcfapp.umiacs.umd.edu:8080/esdi/index.jsp). Após realizar o "download" dos arquivos, procedeu-se com a etapa de classificação, que foi desenvolvida de forma idêntica para cada uma das cenas e descrita detalhadamente a seguir.

Utilizando-se o software Idrisi versão 32.2 (EASTMAN, 2001) procedeu-se a interpretação visual das cenas, na qual cada um dos IDs existentes na imagem foi analisado e reclassificado. Nesta reclassificação o ID analisado adquiriu um novo valor numérico, este agora pertencendo a uma das dez categorias de cobertura do solo: pasto, culturas perenes, vegetação natural remanescente, cana-de-açúcar, reflorestamento, corpos d'água, culturas temporárias, solo exposto, área urbana e outros.

Optou-se por realizar este tipo de classificação pelo fato de que neste método há, de forma expressiva, o máximo uso do bom senso e do olho clínico do interpretador, que não é a máquina (computador, como em alguns métodos de classificação), mas sim o usuário. Neste sentido, em situações onde pixels com ID cuja resposta espectral pudesse gerar dúvidas de interpretação, características complementares tais como posição do pixel na paisagem, forma do polígono formado pelo conjunto de pixels com mesmo ID, comparação com pixels vizinhos, entre outras, proporcionaram um ganho de informações e uma maior certeza no momento da classificação. 
Por sua vez, os arquivos vetoriais georreferenciados sobre os limites das Unidades de Conservação foram adquiridos junto ao Laboratório de Geoprocessamento do Instituto Florestal de São Paulo. Os arquivos foram rasterizados e, por meio do comando "buffer" do software Idrisi, foi gerado uma faixa "buffer" de 3.000 metros no entorno de cada UC. O uso da terra nesta faixa constituiu o real objeto de estudo deste trabalho. $\mathrm{O}$ valor 3.000 metros foi adotado arbitrariamente neste estudo, considerando-se que nesta extensão de faixa os cuidados com o uso da terra deveriam ser máximos, visando a minimização da pressão ambiental e efeitos maléficos da vizinhança nas bordas das UCs.

Uma vez estando completamente reclassificada cada cena e com todos os buffers concluídos, promoveu-se o recorte da cena em relação ao perímetro (com buffer) de cada UC aplicando-se o comando "overlay" do Idrisi.

Após isto, promoveu-se o isolamento da faixa "buffer" de cada cena, excluindo-se as áreas das UCs e ficando somente com a real área de interesse, que é a faixa de 3.000 metros de entorno. Finalmente calculou-se a área de cada classe de cobertura para a faixa buffer de cada UC e os valores foram transformados em porcentagem.

\section{RESULTADOS E DISCUSSÃO}

Embora a checagem da "verdade de campo", isto é, a comparação dos mapas elaborados com situação real e atual de uso (a qual normalmente é feita através de visitas aos locais de estudo) não foi efetuada, será verificado pelo texto discorrido a seguir que os dados aqui obtidos são, em sua maior parte, concordantes com as informações obtidas e comparadas na literatura. Isto confere uma certeza na classificação e permite a validação dos dados aqui levantados. A mesma justificativa pode ser dada quanto a data das imagens, o que sugere que o uso da terra no entorno das UCs parece não ter sido expressivamente modificado desde as datas da passagem do satélite até os dias atuais.

Conforme é mostrado na Tabela 1, comparativamente pode-se notar que há uma notável variação da cobertura do solo entre as três áreas de estudo. O P.E.M.D. foi a UC que apresentou maiores valores de pastagem em seu entorno $(\approx 43 \%)$, enquanto que o P.E.V. apresentou aproximadamente $12 \%$ deste tipo de cobertura e o P.E.I. somente $\approx 2 \%$. Em termos de culturas perenes e temporárias os números apontam uma ocupação mínima para estes tipos de cobertura nas três UCs, valendo o mesmo comentário para a classe área urbana. 
Para o P.E.I. as culturas que normalmente são cultivadas na região (bacia hidrográfica do rio Ribeira do Iguapê) são o chá e a banana (SÃO PAULO, 1998). Já para o P.E.M.D. o fato de não ter sido observada a ocorrência de culturas no entorno da UC é concordante com os mapas agrícolas elaborados pela Coordenadoria de Assistência Técnica Integral (CATI, 2003), que indicam que para a região do pontal do Paranapanema há uma paupérrima ocorrência de culturas, porém uma ampla ocorrência de pastagem, mais especificamente uma forte ocorrência de capim braquiária. Ainda, conforme verificado junto aos mapas da CATI, por sua vez, o P.E.V. situa-se na fronteira da região cafeeira "Alta Mogiana" e também numa região com expressivo potencial de produção de laranja. Contudo, verifica-se pelos dados aqui apresentados, que estes tipos de cultura quase não invadiram os limites próximos ao P.E.V., isto é a faixa de 3.000 metros de entorno aqui analisados.

Para o caso das áreas urbanas, Soares, Bensusan e Ferreira Neto (2002) comentam que para o P.E.M.D. há realmente um franco predomínio de comunidades rurais no entorno do parque, comunidade cujos proprietários são de pequeno, médio e até de grande porte de posse de terra. O mesmo comentário pode ser atribuído ao P.E.V., porém trata-se não de comunidades rurais, mas sim, na sua maior parte, de terras pertencentes a empresas ligadas à agroindústria canavieira e/ou de reflorestamento.

Tabela 1 - Cobertura do solo na faixa de entorno de 3.000 metros, conforme a classe de cobertura, para cada uma das três Unidades de Conservação.
U.C.'s $\rightarrow$
P. E. M. do Diabo
P. E. de Vassununga
P. E. Intervales

$(\%)$

$(\%)$

$(\%)$

\begin{tabular}{lrrr}
\hline Pasto & 42,886 & 12,111 & 2,100 \\
Culturas perenes & 0,000 & 0,448 & 0,000 \\
Veg. Nat. Remanescente & 23,651 & 9,149 & 96,174 \\
Cana & 11,561 & 34,013 & 0,000 \\
Reflorestamento & 0,000 & 22,679 & 0,000 \\
Água & 15,150 & 2,168 & 0,025 \\
Culturas temporárias & 0,000 & 0,174 & 0,327 \\
Solo exposto & 6,689 & 18,379 & 0,743 \\
Área urbana & 0,000 & 0,000 & 0,535 \\
Outros & 0,062 & 0,878 & 0,098 \\
\hline
\end{tabular}


O P.E.I. foi a única UC em que ocorreu a classe área urbana, embora de pouca significância. Não foi um único polígono, mas sim vários e bastante diminutos, o que pode caracterizar alguns núcleos de moradores, sendo posseiros e/ou Quilombos, conforme comentado em São Paulo (1998).

A classe cana-de-açúcar apareceu de forma predominante no P.E.V., ocorrendo em aproximadamente $34 \%$ da área investigada. No P.E.M.D. este valor foi de aproximadamente $11 \%$ e no P.E.I. não houve registro. A classe solo exposto, a qual é intimamente relacionada com a cana, teve uma ocorrência muito similar a esta cultura, sendo que para o P.E.I., embora não ocorresse cana, ocorreu uma diminuta área de solo exposto, a qual pode ter sido confundida com pastagem ou realmente ser solo exposto (clareira em floresta ou área de mineração, por exemplo). De forma geral os dados aqui apresentados são concordantes com os mapas apresentados pela CATI (2003), ou seja, na região do P.E.V. existe uma ampla ocorrência da cultura de cana por estar na zona canavieira de Ribeirão Preto. Por sua vez, o pontal do Paranapanema possui potencial médio para a exploração da cana e o vale do Ribeira (região do P.E.I.) apresenta fraca ocorrência desta cultura.

A vegetação natural remanescente, seguramente a classe de cobertura do solo de maior interesse para a conservação da biodiversidade das UCs, mostrou ampla ocorrência no P.E.I. $(\approx 96 \%)$. De fato, esta é a região mais preservada do Estado de São Paulo e também o P.E.I. é, felizmente, cercado por outras UCs. Na porção nordeste do parque se encontra o P. E. Carlos Botelho, na porção oeste existe o PETAR (P. E. Turístico do Alto Ribeira) e ao norte e sul, o parque é cercado pela Estação Ecológica Xitué (São Paulo, 1998). Desta forma, o P.E.I. talvez constitua uma das UCs paulistas com menores problemas de invasão, riscos de incêndios originados no entorno, entre outros.

O P.E.M.D. apresentou valor intermediário de vegetação natural remanescente $(\approx 23 \%)$. Os fragmentos florestais ocorreram de forma relativamente uniforme ao longo da área de interesse, havendo um fragmento notável na porção noroeste da área do parque. Algumas diferenças nesta classe foram observadas quando comparou-se o mapa aqui elaborado com aquele apresentado no atlas do Biota (FAPESP, 2003). No atlas, o número de fragmentos é bem menor, por duas prováveis razões. A primeira é com relação a data da imagem aqui utilizada (1987) - isto pode ter tido alguma influência, uma vez que o pontal do Paranapanema é uma região historicamente disputada por classes e entidades sociais (VALLADARES-PADUA, PADUA e CULLEN JR., 2002), que ora não consideraram nem um pouco relevante a questão da preservação de áreas remanescentes não protegidas por lei e estes fragmentos que apareceram no 
mapeamento do presente estudo, os quais já não aparecem nos mapas do Biota, desapareceram e foram substituídos muito provavelmente por pastagens.

A segunda razão é quanto à metodologia de mapeamento: o mapa do Biota foi elaborado por um processo de fotointerpretação de imagens de satélite com digitalização em tela dos fragmentos de vegetação - neste sentido, fragmentos de muito pequeno porte podem não ter sido considerados no processo de digitalização. Por outro lado, a metodologia utilizada no presente estudo permitiu considerar fragmentos de até $900 \mathrm{~m}^{2}$, uma vez que a menor unidade de mapeamento (pixel) é um quadrado de 30 metros de lado.

Já o P.E.V. apresentou o menor valor de vegetação natural remanescente $(\approx 9 \%)$ no seu entorno, dado o intenso uso da terra que ocorre na região. Esta classe se apresenta em pequenos fragmentos espalhados de maneira razoavelmente uniforme ao longo das áreas de entorno das glebas do parque, inclusive no lado oposto do rio Mogi-Guaçú, que corta a área de interesse (área de 3.000 metros de entorno da UC). Entretanto, o mapa aponta que não há fragmentos de vegetação natural dispostos imediatamente nas fronteiras das glebas (que estariam praticamente conectados), tal como aconteceu com as outras duas UCs. Isto muito provavelmente prejudica bastante a dinâmica ecológica da região, principalmente em relação à movimentação de animais não alados para fora das glebas.

O reflorestamento apontou uma larga ocorrência no P.E.V., ocorrendo em aproximadamente $22 \%$ no entorno das glebas do parque e, realmente, é uma região cuja atividade é bastante intensa, onde o objetivo do reflorestamento é, principalmente, a obtenção de matéria-prima para fabricação de papel e celulose. Fato curioso foi a não ocorrência deste tipo de cobertura no entorno do P.E.I.. Para esta UC, os mapas da CATI (2003) e do atlas eletrônico do programa Biota (FAPESP, 2003) apontam esta região do estado de São Paulo como sendo de alto potencial de ocorrência de reflorestamento e isto foi verificado em outras oportunidades em que se trafegou pelo entorno da UC.

Esta diferença de mapeamento possui duas prováveis causas: a) confusão por parte do interpretador da imagem, pois é uma área de relevo bastante acidentado e complexa para ser interpretada sob qualquer método, ou b) as empresas da área de reflorestamento terem efetivamente deixado uma faixa de vegetação natural por uma questão legislativa ou mesmo estratégica. Para o caso do P.E.M.D. a não ocorrência de áreas com reflorestamento deve-se a uma simples razão: na porção centro-oeste do Estado de São Paulo praticamente não ocorrem áreas de reflorestamento por uma questão histórico-econômica, ou seja, desde o início do século 
passado não houve interesse em se promover o plantio de espécies florestais nestas regiões porque o grande centro consumidor (região metropolitana de São Paulo) estava longe e a atividade apresentava-se economicamente inviável (KRONKA, 2002).

A classe "água" mostrou maior ocorrência no P.E.M.D., onde uma expressiva parte dos seus limites desta UC confronta com as águas do rio Paranapanema, daí um valor relativamente alto (aproximadamente 15\%). O P.E.V. apresentou valor bem menor porém mais expressivo que o P.E.I., pois uma das glebas do parque (Maravilha) possui parte de seus limites confrontando com as águas do rio Mogi-Guaçu. Já o P.E.I. apresentou valor bastante modesto para esta classe de cobertura e esta classe pode estar sendo representada por pequenos açudes e lagoas que eventualmente ocorrem ou são construídos na região.

Finalmente, a classe "outros", a qual teve sempre valores muito pequenos, é representada por situações que realmente ficou impossível a distinção e classificação do(s) pixel(s).

Todo este cenário de cobertura do solo do entorno que foi exposto e descrito propicia algumas discussões a respeito das possíveis pressões ambientais que as UCs podem estar sofrendo. Os resultados indicam que as UCs P.E.M.D. e P.E.V. são as que largamente sofrem as maiores pressões da área de entorno devido ao uso descontrolado e indiscriminado das terras do seu entorno imediato (faixa de 3000 metros). A soma das porcentagens de pasto + cana + solo exposto para o P.E.M.D. resulta num valor $61,136 \mathrm{e}$ para o P.E.V. de 64,503, portanto similares. Estes usos da terra (considerase o solo exposto destinado ao cultivo da cana-de-açúcar), possuem uma baixíssima permeabilidade para a fauna (KORMAN, 2003; PIRES ET AL., 2002), além do risco de incêndio quando o manejo da área for na base do palito de fósforo.

O P.E.V. sofre ainda um agravante adicional: a presença da rodovia Anhangüera, a qual corta as glebas Capetinga (daí ter-se originado as glebas leste e oeste) e esta desenvolve-se ao longo de um dos lados da gleba Pé-de-Gigante. Além de dificultar as tentativas de interligação das glebas, conforme proposto por Korman (2003), ainda certamente confere periculosidade ligada a incêndios, erosões, atropelamentos de animais silvestres, entre outros impactos ambientais.

Logicamente outros tipos de pressões ambientais não puderam ser aqui verificados, os quais são verificados somente em atividades de campo, algumas delas relatadas por Korman (2003): presença de lixo, focos de queimadas de dimensões menores (a tecnologia aqui utilizada permite somente a detecção de grandes focos), presença de armadilhas e cevas nas zonas de fronterias das UCs (o que evidencia interesse e existência de 
atividades de caça da fauna silvestre), áreas com ocorrência de erosão em diversos estágios de desenvolvimento.

Para o P.E.I., o risco ambiental de maior expressão que ocorre parece não estar somente no entorno do parque mas também dentro dele, que é a extração ilegal de palmitos (Euterpe edulis), não só na região do P.E.I. mas por toda a região de Mata Atlântica (SÃO PAULO, 1998). Trata-se de uma espécie em extinção e que é clandestinamente explorada por moradores da região e posteriormente comercializada no grandes centros urbanos. Segundo São Paulo (1998) além do problema da própria extinção desta espécie existe ainda o fato desta espécie ser considerada recurso-chave, que caracteristicamente desempenha um papel proeminente no sustento da comunidade de animais frugívoros durante períodos de escassez de alimentos. Deste modo, há o início de atividades de manejo sustentado e exploração racional desta espécie para que se possa conciliar os interesses econômicos da população da região com os limites ecológicos da espécie em questão (SÃO PAULO, 1998).

$\mathrm{Na}$ região ocorrem expressivas jazidas de calcário (SÃO PAULO, 1998), o que desperta o interesse de empresas mineradoras em atividades de lavra, dentro e fora das UCs da região. Desta forma sempre há uma "quebra-de-braço" judicial entre as empresas, o Departamento Nacional de Produção Mineral, a Secretaria Estadual de Meio Ambiente de São Paulo e instituições/associações da região interessadas e/ou preocupadas com o futuro da UC e da qualidade de vida da população regional.

\section{CONCLUSÕES}

O presente trabalho indicou que das três Unidades de Conservação aqui estudadas, o P.E.I. é o que possui seu entorno com melhores condições de proteção à área do parque. Por outro lado, o P.E.V., embora tenha uma porção expressiva do seu entorno ocupada por reflorestamento, possui também expressivas áreas ocupadas pela cultura da cana-de-açúcar, o que pode conferir uma alta pressão ambiental nas fronteiras com a cana e tornando ainda mais pronunciado o efeito de borda. Já o P.E.M.D. possui como principal ocupação de entorno a pastagem, que, assim como no P.E.V., pode sofrer uma alta pressão ambiental nos ecótonos pastagem/floresta e também aumentando o efeito de borda e isolamento.

\section{AGRADECIMENTOS}

O autor é grato ao Laboratório de Geoprocessamento do Instituto 
Florestal de São Paulo, pelo uso compartilhado dos materiais digitais relacionados no trabalho e ao pesquisador Dr. Manuel E. G. Guandique (CENA-USP) pela revisão do texto.

\section{REFERÊNCIAS}

CALIJURI, M. L. Sistemas de informação geográfica. Apostila do curso sobre sistemas de informação geográfica ministrado no programa de pós-graduação "Ciências da Engenharia Ambiental" na Escola de Engenharia de São Carlos - Universidade de São Paulo (EESC - USP), 115 p.,1996.

CATI (Coordenadoria de Assistência Técnica Integral). Mapas agrícolas do estado de São Paulo. www.cati.sp.gov.br, 2003 (ano da consulta).

EASTMAN, J. R. Idrisi 32, Release 2: Tutorial. Worcester: Clark University - USA,. 237p.,2001.

FAPESP, Programa Biota - Instituto Virtual da Biodiversidade - Atlas eletrônico. http://sinbiota.cria.org.br/atlas, 2003 (ano da consulta).

JORGE, M. C. L. et al. Riqueza e abundância de pequenos mamíferos em ambientes de cerrado e floresta, na reserva cerrado Pé-de-Gigante, Parque Estadual de Vassununga (Santa Rita do Passa Quatro), Naturalia. São Paulo. v. 26, 287 - 302p.,2001.

KOFFLER, N. F. Uso das terras da bacia do Rio Corumbataí em 1990. Geografia. Rio Claro, v. 18, n. 1, ,135 - 150p., 1993.

KORMAN, V. Proposta de interligação das glebas do Parque Estadual de Vassununga (Santa Rita do Passa Quatro, SP). 2003. Dissertação (Mestrado). Escola Superior de Agricultura Luiz de Queiroz - USP. Piracicaba-SP. 2003.

KRONKA, F. J. N. Inventário Florestal das Áreas Reflorestadas do Estado de São Paulo. São Paulo: Secretaria do Meio Ambiente / Instituto Florestal. 2002. 184 p.

OliveirA, J. B. et al. Mapa Pedológico do Estado de São Paulo, Legenda Expandida, Campinas: Instituto Agronômico. 64 p.,1999.

PIRES, A. S. et al. Frequency of movements of small mammals among Atlantic Coastal Forest fragments in Brazil. Biological Conservation. Amsterdam, v. 108, 229 - 237p., 2002.

ROSS, J. L. S. Geografia do Brasil. São Paulo: Edusp. 2003. 548 p.

SÃO PAULO, FUNDAÇÃO PARA A CONSERVAÇÃO E PRODUÇÃO FLORESTAL. Parque Estadual Intervales: Plano de Gestão Ambiental. São Paulo: Secretaria do Meio Ambiente do Estado de São Paulo, 231 p., 1998. 
SCHLITTLER, F. H. M. Fitossociologia e ciclagem de nutrientes na floresta tropical do parque estadual do morro do diabo (região de pontal do paranapanema, estado de São Paulo). 1990. Tese (Doutorado) Instituto de Biociências - UNESP. Rio Claro-SP. 1990.

SOARES, M. C.; BENSUSAN, N.; FERREIRA NETO, P. S. Entorno de Unidades de Conservação: Estudo de Experiências com UCs de Proteção Integral. Rio de Janeiro: Estudos, Funbio, n. 4. 57 p., 2002.

VALLADARES-PADUA, C.; PADUA, S. M.; CULLEN JR., L. Within and surrounding the Morro do Diabo State Park: biological value, conflicts, mitigation and sustainable development alternatives. Environmental Science and Policy. Amsterdam, v. 5, 69 - 78p., 2002, VIANA, V. M.; PINHEIRO, L. A. F. V. Conservação da biodiversidade em fragmentos florestais. Série Técnica IPEF. Piracicaba, v.12, n. 32, 25 42p., 1998. 